\section{form}

Vol I3, No 6 (2020) https://doi.org/10.7577/formakademisk.3872

Kari Saasen Strand

Assistant Professor

Oslo Metropolitan University Kari-Saasen.Strand@oslomet.no

Peter Haakonsen

Assistant Professor

Oslo Metropolitan University

Peter.Haakonsen@oslomet.no

Laila Belinda Fauske

Professor (PhD)

Oslo Metropolitan University

Laila-Belinda.Fauske@oslomet.no

\title{
E-textiles: An interdisciplinary approach
}

\section{Problem solving in an educational context}

\begin{abstract}
This article aims to shed light on e-textiles as a fusion of different skills. The empirical starting point is a workshop on e-textiles offered to a group of teachers attending a continuing education course in art and design. The study adopts self-ethnography. Using anonymous reflection notes from the workshop, the article discusses e-textiles as an arena to enhance problem solving through practical explorational work. This involves interdisciplinarity, crafting skills and computational thinking. Focusing on two categories, namely I) material knowledge and sustainability and II) electronics knowledge and interdisciplinarity, this study shows that time is an important factor when exploring e-textiles in an educational context. In etextiles, crafting, circuitry, programming and sustainable thinking can be combined in an interdisciplinary and productive mash-up encouraging problem solving.
\end{abstract}

Keywords:

E-textiles, problem solving, sustainable thinking, interdisciplinarity, art and design education

\section{INTRODUCTION: E-TEXTILES, AN APPROACH TO PROBLEM SOLVING}

Since 2011, the Department of Art, Design and Drama at Oslo Metropolitan University has run several projects and courses on e-textiles for students and teachers. The focus has been on practical and aesthetic exploration work, which includes redesigning existing products and materials. Electronics are integrated into textiles through hand sewing, with conductive threads and other electronic components, such as LEDs, resistors, sensors, microcontrollers and batteries. In this way, the electronic components expand or change the function of the fabric. Aesthetic expression is emphasised, and the components 
become a natural part of the design. Students learn to expand their knowledge and develop their skills, both technical and aesthetic, as they experiment. Creativity, tinkering, perseverance and debugging are emphasised rather than a fixed or closed knowledge system by accentuating experimentation as part of the learning process. The aspects of redesign invite reflection on sustainability as part of art and design.

With the increase of makerspaces in schools, e-textiles share common ground with science and technology. Makerspaces enable the combination of creative problem solving with craft, design and technology. This combination can also be relevant for interdisciplinary projects in primary and secondary schools, lately referred to as Science, Technology, Engineering and Mathematics (STEM)based projects. Here, the term STEM refers to engineering subjects in K-12. However, the term STEAM (Science, Technology, Engineering, Art and Mathematics) is often mentioned in contexts where art subjects give STEM subjects a dimension of creativity and design thinking, along with a reminder that not every assignment has just one correct answer (Connor et al., 2015). Aside from the Art and Crafts subject, e-textiles are closely related to other subjects, such as Science, Mathematics and Entrepreneurship. It is also closely related to the maker movement, in which tinkering and do-it-yourself activities are encouraged (Berland, 2017). STEAM concepts, amongst others, are inherent in e-textiles. This position makes e-textiles an interdisciplinary field of making. Textiles have very wide and rich applications. People wear textiles, and textiles are used in furniture and in the interiors and exteriors of buildings. Combining textiles and electronics produces e-textiles (electronic textiles). These include smart textiles, in which computational elements are added, such as microcontrollers and sensors programmed to read the environment (e.g. temperature, gas, light, movement, pressure). E-textiles are expanding widely as materials used not only in sportswear, safety wear and health care but also in costumes, scenography and even in personal expression (e.g. https://cutecircuit.com/).

The Norwegian Directorate for Education and Training [Utdanningsdirektoratet, Udir] has published a description of key concepts and approaches within computational thinking [algoritmisk tenkning in Norwegian] in connection with the existing curricula in Art and Crafts (Bocconi et al., 2016; Udir, 2019; Wing, 2017). These concepts and approaches can be seen as a framework for how students can develop abilities to solve problems and recognise patterns to solve undefined problems in the future. Computational thinking is about abstraction; it can be seen as a skill and can be applied with or without a computer (Wing, 2017). Being able to break a problem or task into smaller parts and being able to create, tinker, debug, collaborate with peers and persevere are some of these concepts and approaches (Barefoot, n.d.; Udir, 2019). These approaches have some similarities with the concepts of problem solving and problem finding, as described by Sennett (2008). Both computational thinking and sustainability are strongly grounded in the Norwegian curricula for levels 1-10 (Udir, 2020a, 2020b, 2020c).

The empirical starting point for this article is a workshop on e-textiles offered to a group of teachers attending a continuing education course in art and design. The article builds upon data gathered through reflection notes written by the attending teachers. Even though e-textiles are not a defined area per se in the school subject of Art and Crafts, they are in a unique position, in which traditional textile crafting meets newer materials, such as electronics and programming software, a dichotomy of soft and hard materials (Searle et al., 2016). The dual intention of having the reflection notes as part of the workshop was to strengthen the participants' awareness of their own learning processes and to encourage reflection on how such awareness can enhance their own teaching in Art and Crafts. This article addresses the following research question: What kinds of possibilities emerge regarding problem solving through practical explorational work in e-textiles? 


\section{E-TEXTILE: MAKING KNOWLEDGE}

As part of a modern society, we meet challenges and problems that are new to us. We have recently been facing a global pandemic that has forced us to work together locally, nationally and globally. Both makerspaces and small textile factories have contributed to developing and producing infection control equipment. Children, who have not been able to go to school, have been taught through online schooling. Teachers have been forced to turn their teaching upside down in order to find new ways to communicate, motivate and facilitate learning. Makerspaces, textile factories and schools have faced their challenges in their own way and tapped into their creativity for new answers.

\section{Problem finding and problem solving}

According to Sennett (2008), an instant relation or rhythm occurs when moving between solving and finding new problems. This process differs from one in which the solution to a problem is regarded as fixed or already set. The process of moving back and forth between solving a problem whilst simultaneously looking for new ones is shared by the ancient potter and the modern programmer (Sennett, 2008). This relates to how problem solving is connected with computational thinking in the curricula for schools in Norway. As Wing (2017) describes, computational thinking is related to both formulating and solving problems. Like computers, humans can compute. Formulating problems before making abstractions and breaking the problem into smaller parts are essential in the process of expressing possible solutions (Wing, 2017). In the abstracting process, defining patterns, generalisation and parameterisation are important concepts. These concepts are applicable to creative processes for students working with e-textiles, in which elements of experimentation and ideation in an open-ended design process lead towards ideas and solutions combining textiles and electronics. Both concepts concern an open process of crafting, involving searches for new possibilities, solutions and improvements.

\section{Fusion of the soft and hard fields}

The making professions are concerned with the built environment and the manmade world. These professions consist of architects, designers and artists, as well as teachers in Art and Crafts (DuninWoyseth, 2008; Dunin-Woyseth \& Nielsen, 2004; Fauske, 2016). The making disciplines, a term that has grown from the academisation of the making professions, are concerned with the knowledge inherent in the process of making and are strongly reliant on Ryle's concept of knowing how (Dunin-Woyseth \& Michl, 2001). Dunin-Woyseth and Michl (2001) define knowledge based on the making professions as making knowledge. The making disciplines aim to maintain the distinctive character of the making professions and at the same time fulfil the established criteria for traditional research. The teachers attending the workshop were all aiming to expand their making knowledge and gain specific skills and knowledge in e-textiles through practical work with materials and tools and exploration of different technical solutions. Knowing how deals with the knowledge gained through practice and reflection (Ryle, 2000). Practice and reflection (or theorising) cannot be treated separately, as they are interwoven. This perspective implies that when observing a process or taking part in a conversation, one needs to understand what is going on. If not, one can only appreciate what is observed or shared but not fully understand it: 'The knowledge that is required for understanding intelligent performances of a specific kind is some degree of competence in performances of that kind' (Ryle, 2000, p. 53). Working with etextiles demands an interaction between practice and reflection. E-textiles integrate craft, circuitry and code and can be described as a mash-up that challenges our cultural understandings, not least when it comes to highly gendered domains, a topic that Searle et al. (2016) address in Is Sewing a "Girl's Sport"? These scholars shed light on how traditional textile crafts, such as sewing, knitting and felting, have a long history and are often seen as 'soft' and 'feminine' fields, whereas electronics and computing are newer fields and are traditionally seen as 'hard' and 'masculine' (2016, pp. 73-74). However, e-textiles 
open up a broad spectrum of questions and issues. They combine traditional textile craftsmanship with electronics and computational knowledge, material knowledge and problem solving. They are a highly complex field. The fusion of the soft and hard fields expands or changes both the function and the experience of the material.

E-textiles can give the maker broader perspectives on something traditional and challenge both fixed mindsets and preconceived ideas on sustainability. E-textiles go beyond 3D printing and laser cutting. The 'screen' begins with the use of needles, thread and fabric (Searle et al., 2016, p. 83). Etextiles require knowing how rather than just knowing that. Figure 1 illustrates a bracelet made by the main author. It is redesigned using old curtains, made with both a sewing machine and by hand sewing. A simple circuit consisting of one yellow LED, a coin cell battery and textile battery holder, and metal sew-on snap buttons. When these buttons are connected, the circuit is closed, and the LED lights up. Everything is connected with conductive thread. In the working process, aesthetics, form and function were emphasised. To sum up, e-textiles are analogue yet digital, soft yet hard. In an educational setting, this is interesting, as it challenges the maker by requiring them to experience different materials and techniques in order to know what is best for which purpose.

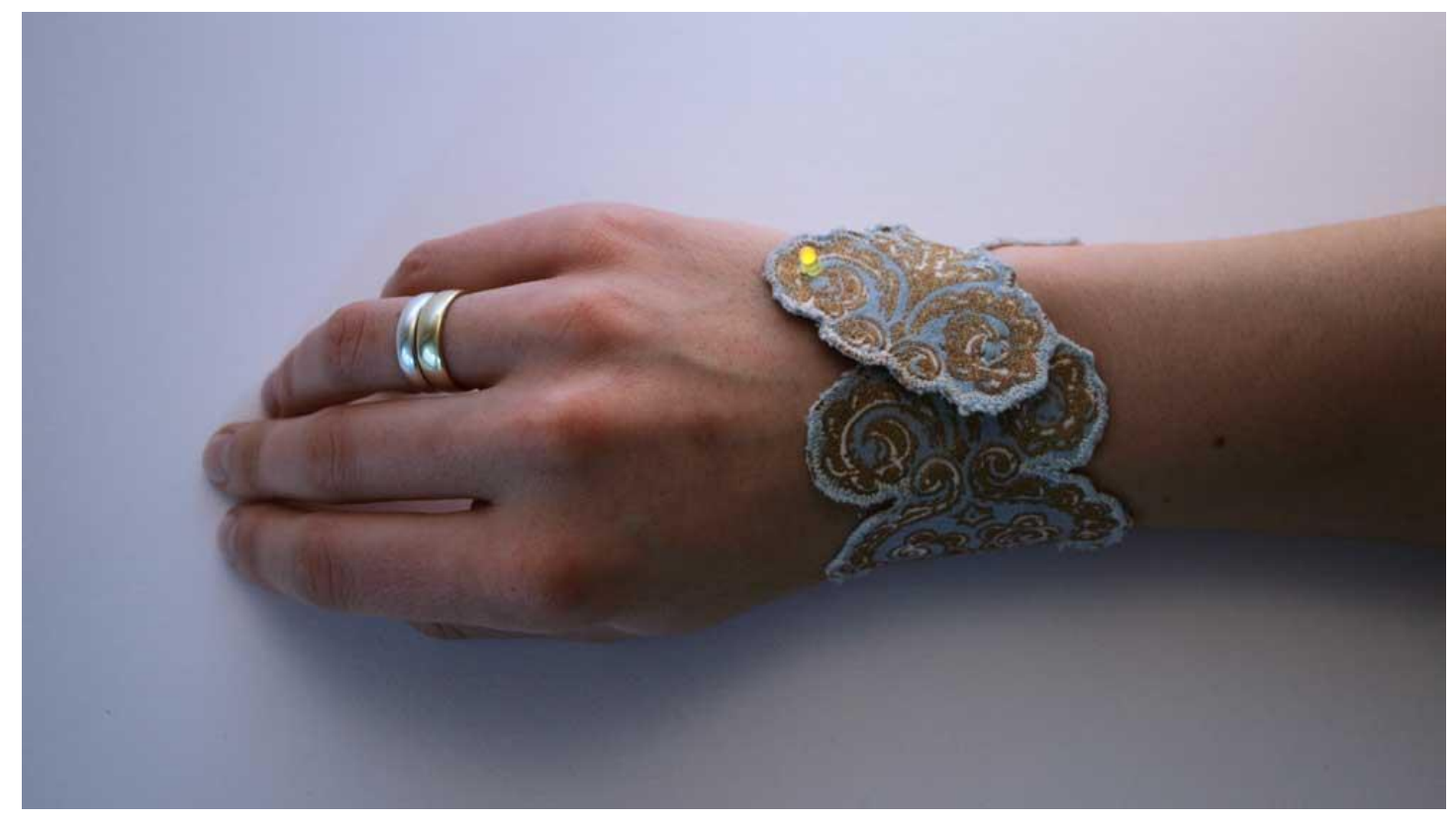

FIGURE 1: Example of an e-textile bracelet made by the main author. Reflections on design, aesthetics and material reuse (redesign of a curtain) were considered during the making of the bracelet.

Traditionally, students at a university are taught within the boundaries of their discipline. Interdisciplinary learning, on the other hand, aims to integrate knowledge from different disciplines. This learning process builds a more comprehensive understanding of what is studied (Holley, 2009). Etextiles challenge students, as it demands an interdisciplinary approach to problem solving-an understanding of electronic circuits and computing (if applicable) and basic skills and knowledge of art and design. The reflection notes written by the teachers attending the workshop shed light on both challenges and possibilities when exploring materials and techniques in an interdisciplinary project.

\section{DESIGN OF THE STUDY}

This article aims to shed light on the complexity of e-textiles through the reflection notes written by the teachers attending an e-textiles workshop. More specifically, this paper addresses the following question: What kinds of possibilities emerge regarding problem solving through practical explorational 
work in e-textiles? The participants were teachers in Art and Crafts in a lower secondary school and an upper secondary school and were undertaking a continuing education course for teachers in art and design. This was a one-day workshop that lasted for six hours and had a subsequent coursework requirement, in which the participants were to complete the assignment at home and then write their reflection notes. The main idea behind asking for reflection notes was to obtain insights into the participants' reflection on action (Schön, 1983).

\section{Short description of the workshop}

The participants were introduced to e-textiles through a novel task-making a bracelet with two to three LEDs and an on/off button. By using more than one LED, they learned about parallel connections and were forced to rethink their designs and how to avoid short circuits if crossing the conductive thread. The participants were then introduced to the coursework requirement to work with textiles, redesigns and electronics. They were expected to use available materials, and the task was to design a reflective product with LEDs, a reflex textile and other textiles/materials. During the working process, form, functionality, aesthetics and practical application were to be considered. The assignment was to be finished at home within approximately three weeks.

This article relies on the responses indicated in the reflection notes that are required as part of the coursework. Nineteen participants were asked to reflect on their own experiences from the assignment: what worked, what did not work, what could have been done differently and what opportunities exist in such products and challenges. They were also asked to reflect on how they would do this task in a teaching context at their own school. Consent to use the reflection notes in this research project was obtained after the submission deadline.

\section{Familiarity as the empirical starting point-challenges and opportunities}

When a researcher wants to know more about what is going on in a context where they are active participants, Alvesson (2003) suggests using familiarity as an empirical starting point. In line with such an approach, questions that have grown over time based on the experience of teaching students at a variety of workshops and courses have formed the basis for this study: What goes on when the participants work actively at the workshop? How do students gain knowledge and skills through explorative work with different materials and techniques? How do teachers reflect on their own learning and on the potential for teaching students in primary and secondary schools?

According to Alvesson (2003), studying activities and settings that are familiar to the researcher can be challenging. This type of research can include conducting a study of one's own department, studying interactions with students or looking closer at issues not yet discussed within a specific community. Such challenges can be taken-for-granted assumptions, taboos, blind spots and the wish not to upset colleagues (Alvesson, 2003). However, there are also obvious advantages when studying a familiar context. Turning a topic one already knows or knows a good deal about into a research project can bring new insights to the forefront. Undertaking a systematic study at one's own workplace can improve the practice at such a workplace and create more awareness amongst colleagues about what has been studied. A research study can also inform the broader community and, as such, be regarded as a contribution to a continuous knowledge-building process. Knowledge building is considered ' (...) the creation and improvement of knowledge of value to one's community' (Scardamalia \& Bereiter, 2020 , p. 8). The making disciplines can be seen as an outcome of such a knowledge-building process.

Conducting a research study at one's own workplace demands active reflection on the challenges described by Alvesson (2003). In the present study, looking critically at the design of the study and searching for taken-for-granted assumptions and blind spots as hindrances to the analysis and discussion of the findings have been considered important. Using familiarity as a starting point is characteristic of what Alvesson (2003) describes as self-ethnography. This implies 'creating knowledge through trying to interpret the acts, words and material used by oneself and one's fellow organizational members from a distance' (Alvesson, 2003, p. 176). Self-ethnography must not be confused with autoethnography. Whilst auto-ethnography is personalised, meaning that the researcher studies their own lived experiences, self-ethnography is concerned with the researcher's cultural and professional context 
(Alvesson, 2003; Fauske, 2013). The research question in this study has grown from a professional curiosity aiming to meet the new demands in curricula for primary and secondary schools and to contribute to the knowledge-building process of teacher training in Art and Crafts.

\section{ANALYSIS OF REFLECTION NOTES}

During the workshop, the participants only used LEDs, conductive thread, batteries and an on/off switch of some sort. No programming was involved. Conductive thread was used instead of wires. This thread is soft and made of metal fibre, and it can be joined with electronic components, such as LEDs, by sewing or tying the thread ends. Because the thread is made of metal, soldering can also be used to join the thread, and one participant attending the workshop chose to do this. The conductive thread is uninsulated, and if the circuits intersect or if a small fibre from the thread loosens and enables contact between the positive and the negative sides of the circuit, short circuits will result. This is a slightly softer way to introduce electronics than to go directly to wires and soldering. However, this task may require more skills to solve the task. The weakness of e-textile products made with conductive thread often involves the sewing techniques and the battery holder. The battery holder is a weak spot because if it is self-made, there is often a bad connection between the positive and negative poles, loose threads that make a short circuit or a battery pocket that is not tight enough. It requires the maker to have some skills in sewing techniques and an understanding of electronic circuits as a form of craftmanship. A disadvantage of poorly made products is that they will break apart easily and be discarded, as opposed to heavily used favourite objects whose quality is emphasised in both technical and material choices.

Some participants were able to start on their assignment during the workshop, and others were more thorough and detail oriented, wanting to make something aesthetically pleasing, and, therefore, spent the whole workshop completing the bracelet. Lutnæs and Fallingen (2017) point to the joy of making something on your own and relate this to an aspect of sustainability. Creating something new and being able to repair are emphasised as important in this regard. There are some similarities between the aspects emphasised by Lutnæs and Fallingen and the working process of the participants.

\section{Categorising the material}

When analysing the material, we chose to divide the responses into different categories. Categorising the answers gave us a better opportunity to analyse the responses according to the research question. The categories were not fixed in advance but were defined during the analysis. The main author's previous experience, gained through teaching e-textiles, has influenced the definition of categories (cf. self-ethnography). As such, the categories build on former experiences but at the same time aim to contribute to the knowledge-building process of e-textiles as part of teacher training in Art and Crafts.

Given the research question, we were looking closely for answers that would shed light on problem solving and sustainability through interdisciplinarity, technical knowledge and knowledge of materials. However, a creative working and learning process is often rich, complex and without clear boundaries. This made it necessary to define several categories whilst working on the analysis. Thirteen categories were defined: a) design process/idea development, b) design/aesthetic experience/quality, c) documentation and presentation, d) innovation and makerspace, e) gender perspective, f) knowledge of materials, g) sustainability, h) collaboration, i) hand crafting and sewing knowledge, j) electronics knowledge, k) interdisciplinary, I) didactics/reflection and $\mathrm{m}$ ) evaluation. Some answers fall into several categories and thus go crosswise.

In response to the research question, quotes and issues from four of the categories will be presented and discussed: f) knowledge of materials, g) sustainability, j) electronics knowledge and k) interdisciplinarity. In the process, we decided to combine knowledge of materials and sustainability into one category in the analysis. These two categories turned out to be well connected with each other not only in terms of sustainability and environmental issues but also in terms of sustainability being understood as the enjoyment of making. Lutnæs and Fallingen (2017) reflect on the similarities between the making process, i.e. a process in which the body and mind work together, and an ecological way of thinking. Electronics knowledge and interdisciplinarity were also combined into one category, as it 
turned out that when electronic challenges emerged, questions about interdisciplinary opportunities also emerged.

\section{Knowledge of materials and sustainability}

In this category, we searched for issues regarding problem solving, i.e. knowledge of materials and sustainability. What stands out in this category is the respondents' reflections on how they would like to experiment with different, possibly more suitable, materials for their product if more time or a 'next time' was available, which could involve different textiles/materials and different locking mechanisms. These can be interpreted as durable solutions. When reflecting on teaching primary and secondary school students, one workshop participant mentioned glue as an alternative to sewing (for restless students). The possibility of experimenting with different materials was mentioned several times. The following are excerpts of quotes from these two categories:

If there had been more time and opportunity, I would have liked to explore this field even more and in other directions than using LEDs. I therefore chose to place more emphasis on the textile (reflex material), design and method in this assignment so that the method I used was something I could develop and learn from and that my product should be something I could benefit from afterwards. (Respondent 6)

[...] but for next time, I will probably make a variant in which you have access to electronics all the time and thus think even smarter about design and function, and work with a product that has an even more direct link between light and reflection. (Respondent 6)

Present different materials to them because materials reveal many new choices and ideas [...] Often, different materials help form ideas faster. (Respondent 7)

I notice that many young people are presented with the term [design] as an empty and worn-out concept that they associate with new, beautiful and expensive products. Amongst other [things,] luxurious 'coffee table books' with exclusively beautiful pictures gathered in an attractive cover reinforce this notion. The keywords are material abundance and empty object culture. I myself have responded to this task by combining two existing products into one multifunctional product. In other words, $1+1=3$. I think the task fits well into this way of working with design, thus challenging the view of what design can be. Instead of thinking that one should create a new product, one can work on combining pre-existing products to create practical links. This is how you can reduce the number of things you depend on during the day. (Respondent 9)

Here, design could become visible as practical problem solving, and students would gain insight into a design concept that deals with needs and user-friendliness. It does not point to material abundance but is based on basic functions and needs and solutions to everyday problems. Then, one can let the ball roll naturally towards discussing environmentally friendly design and green thinking. (Respondent 9)

As a course leader/teacher of the arts, I believe that in Art and Crafts, embedding values with an environmental perspective is a great opportunity. It is useful to create understanding and insight into the society we live in by teaching about environmental problems. The students will create some products by being able to link them to the consumer society (i.e. the environment). (Respondent 17)

In response to the research question, 'problem solving' as a word is only mentioned once in the reflection notes (Respondent 9). However, when analysing the reflection notes, we can see the description of an open-ended working process, which is typical for problem solving. Respondent 6 reflected on 'next time', indicating that if this had not been a time-limited course, the process would have continued. What is mentioned several times is the use of different materials. Presenting students with a variety of options for materials can broaden their understanding and make them come up with new ideas. An active idea phase in which one explores different materials can be interpreted as a kind of problem solving. Students must use the material they think best solves the task, and this requires the students to have some sort of knowledge of materials. 
Respondent 9 addressed the concept of design as something students in schools often get presented as an empty or worn-out term, in which design is 'associate[d] with new, beautiful and expensive products'. However, Respondent 9 also spoke of design as a chance for the students to 'gain insight into a design concept that deals with needs and user-friendliness'. In the same quote, Respondent 9 reflected on an 'environmentally friendly design and green thinking' as a theme for discussions with students. All in all, Respondent 9 drew attention to the complexity of the term 'design' in the school subject of Art and Crafts, as the term embraces both beautiful and expensive products, problem solving and sustainability.

None of the respondents mentioned the environmental impact that electronic components can have (e.g. batteries, which are commonly used when making small e-textile projects). Environmental challenges were addressed at the workshop, but they were not a major topic. However, redesign was a part of the task, and many addressed redesign and reuse as a natural and important part of the Art and Crafts subject. Respondent 9 mentioned an 'environmentally friendly design and green thinking' when elaborating on teaching design to students in schools. Sustainability is emphasised in the curricula of 2020 (Udir, 2020c). However, trained teachers in Art and Crafts do not necessarily have enough knowledge of electronics to discuss the environmental consequences of these in Art and Crafts education. Redesign, however, has a long tradition as part of the school subject. Perhaps the end justifies the means, with the end being to make small e-textile projects first for greater learning benefits in terms of how to see the possibilities of e-textiles and how to better understand electronic circuits.

\section{Electronics knowledge and interdisciplinarity}

In this category, we looked for issues regarding problem solving and the necessary skills to solve electronic challenges in completing the e-textiles and what the respondents reflect on regarding interdisciplinary collaboration: What can we expect a teacher in Art and Crafts to know about electronic circuits? How do the participants handle these challenges? The following are excerpts from this category:

Even if you plan well, it may not always work out the way it should. May be bad connections or short circuits between threads. Haven't quite found the cause, and it's frustrating. (Respondent 1)

Idea development and the planning phase (with its exploration perspective and market research), the innovation exercise (with new, unknown and demanding materials) and interdisciplinarity (combination of technical and aesthetic solutions, electronics and design) would provide great learning outcomes and motivation for both girls and boys. (Respondent 2)

Craft-wise, there are many challenges that need to be addressed: the battery holder, circuits and the assembly should have been planned, organised and implemented in a different, more thorough (also time-consuming), way. (Respondent 2)

The reflex does not draw attention from the coat itself but plays with it so that the garments highlight one another. The reflex works both in daylight and when it is dark, and the user is satisfied and will use it. For the technical part, however, I will continue to work on it after the assignment so that the reflex can withstand some rough treatment. (Respondent 3 )

Despite careful planning and testing, especially with electronics, this, unfortunately, did not work when the whole bag was sewn together. Unfortunately, I cannot explain why this did not work other than the fact that it is fragile electronics. (Respondent 6)

At my school, this technique fits in with subjects such as Redesign and has interdisciplinary collaboration with Science. I would like to give the students the same task that we have been given to make bracelets with a snap button. I want to try this out with resistors and receive help from colleagues before we start. I haven't done that yet. (Respondent 13)

My experience in this process is that it is fun (but challenging) to get the technique to work; it seems that there are challenges associated with the assembly itself (I especially struggled with the soldering), but it is very satisfying to make it all work. (Respondent 18) 
Several of the answers state that making, for example, a bracelet before undertaking a larger task provides a quick experience of what it takes to make the bracelet light up or provides more understanding of electronic circuits (e.g. Respondent 13). Respondent 3 made a coat in which the LEDs play a role together with the reflex, both to light up the coat in the dark and also for decorative use, and the 'user is satisfied and will use it' (Respondent 3). Reflective materials might not be the best solution compared with external reflexes, but it is more useful to have them as opposed to being hidden away in a drawer (Klepp \& Tobiasson, 2020, p. 107). Some respondents (Respondents 3 and 18) referred to technical issues. This can be interpreted as technical in terms of not only electronics but also material composition, joining techniques and material properties. Respondent 13 showed a solution-oriented approach to challenges in electronics, in which collaboration with other subjects is an important part of a possible task in e-textiles. Respondent 2 wrote about 'innovation exercise', 'interdisciplinarity', 'idea development' and 'the planning phase'.

Time, assembly and planning are issues that seem to recur amongst the respondents (e.g. time to plan a better circuit, time to plan the construction of the product and time to assemble the elements). Most respondents did manage the electronics, but a few did not, stating that it was 'frustrating' and that the electronics were 'fragile' (Respondents 1 and 6, respectively). It may seem that these participants had given up on problem solving regarding electronics. However, as Respondent 6 mentioned in the latter category, 'but for next time, I will probably make a variant in which you have access to electronics all the time and thus think even smarter about design and function'. This may demonstrate that with the right knowledge of materials, electronics would also function better. However, even though things did not always work out the way the participants thought or wanted to, they still showed general positivity and enthusiasm towards the task, and this can be interpreted as the participants envisioning the implementation of e-textiles in a possible teaching class. Would a stronger emphasis on collaboration, giving the participants the opportunity to share ideas with their peers, have an impact on the outcome? This was opposite the situation in which these participants' further development proceeded at home after the workshop.

\section{DISCUSSION}

The research question in this study has grown from a professional curiosity concerning e-textiles as an arena for problem solving through practical explorational work. This involves a wide range of fields, including enhancement of crafting skills, interdisciplinarity, computational thinking and creative thinking. Familiarity was the empirical starting point when performing the study (cf. self-ethnography). The intention has been to create knowledge based on the interpretation of written reflections from a group of trained teachers in Art and Crafts. The result of this study will be used to further develop this type of workshop at the institution, but it is also our intention to contribute to the knowledge-building process of teacher training and, by this, strengthen e-textiles as part of Art and Crafts education.

\section{Time and creative work}

The main finding in this study is the importance of time when exploring new materials. Art and Craft as a school subject has a tradition of giving students experience with practical creative work. Lutnæs and Fallingen (2017) point out that when students are introduced to the limitations and opportunities of different materials, they receive training in handling situations that cannot be predicted, which forces new solutions along the way. This gives students training to be open to unforeseen results and to compensate for these during the process. This can help them develop valuable skills in creative problem solving. The teachers attending this specific workshop had limited time when exploring e-textiles. As seen in the reflection notes, this led to frustration amongst some participants when problems occurred. However, as trained teachers, the participants seemed to manage to transfer their experience to future scenarios in their own classrooms. This is evident in the reflection written by respondent 13: 'I would like to give the students the same task that we have been given to make bracelets with a snap button. I want to try this out with resistors and receive help from colleagues before we start'. The teacher wants 
to integrate the existing assignment in class but wants to explore further together with colleagues before introducing it to the students. Time is of importance when trying out new ideas and exploring new materials; this includes improving and developing one's educational practice.

Teaching e-textiles is very close to teaching in Art and Crafts - it is just another material to work with. However, teaching e-textiles requires that the teacher has skills in sewing techniques, has some sense of textile as a material and knows a bit about electronic circuits. To make a product that works, students need some sort of experience in sewing (i.e. how to thread a needle and do different sewing stitches). This study has shown that this kind of working process is time consuming. The students need time to practice, time to fail and to try again. If conductive thread is used instead of wires and soldering, the thread must be sewn in properly-neatly and thoroughly. Sloppy work usually means bad connections, and it has to be redone. If microcontrollers are added to the e-textile, the teacher has to have some programming competence.

An e-textiles workshop is a way to gain experience with and an understanding of crafting with textiles, electronic circuits and optional programming. This can be a trigger to attract more makers to subjects they are not necessarily experienced with (Searle et al., 2016). On the other hand, workshops with limited time do not allow for in-depth learning and for coming up with good ideasthrough working hard on the ideas, looking at what has been done before, trying out different solutions, failing and trying again (persevering) - in the way that working in a process with a larger timespan does. Perseverance is one of the described computational thinking approaches; it entails staying with the problem longer and not giving up (Barefoot, n.d.). This is an important approach in the school curricula and is connected with problem solving. Sennett (2008) describes problem solving as a rhythm that occurs when moving back and forth between identifying a problem and searching for solutions. One of the findings from the reflection notes was the lack of time, which includes time for planning better, understanding the electronics and putting everything together in a better way. Creative problem solving is a natural part of the design process, and in order to come up with good solutions, time is required to work on ideas. Some students are easily attracted to this process and know exactly what to make and finish within a short period. However, other students need more help and also want to knead their ideas longer, or they need more time because they are not experienced with sewing, electronic circuits or programming. The result can be an unfinished product that does not work or lacks a good design, both aesthetically and functionally, which can inhibit motivation and a sense of achievement. Therefore, it could be important to give students who are doing a maker project, such as e-textiles, enough time to feel both frustrated over failure and triumphant about overcoming challenges and making something completely their own.

\section{Materials and sustainability}

What has been interesting in this study is the participants' creative ideas about the potential of different materials. Creating something completely new from a blank canvas is not necessary to make an e-textile. In fact, an existing textile product can be modified or built upon. This can help trigger the idea phase. Textiles are easily accessible; most students can bring something from home, such as a worn t-shirt, mittens or a hat. Textiles are cheap, and as the material has a history, it can open dialogue. A close relationship with the material can result in less discarding. According to Lutnæs (2015), redesign and seeing opportunities in material reuse are important mindsets in design teaching. Design education that encourages students to reflect on sustainability and meet global challenges empowers responsible citizens. However, not many of the participants focused specifically on sustainability in their reflection notes. What several did reflect on were different ideas about using textiles in school. Textiles are easily available; at the same time, they are a valuable resource because of their property of being easy to redesign or to upcycle to something else. A garment or other pre-existing textile product can be a good starting point for making something new or building upon something that already exists. The reflection notes indicate a consciousness about redesign and sustainability even though it is not explicitly articulated.

The materials often used in e-textile workshops are different types of felt and neoprene. This is because of the qualities of these materials; they do not rake, and they are stable and easy to handle. 
Felt is made of wool or polyester or a mix of wool and polyester, and neoprene is made of synthetic rubber-plastic. However, these materials can be perceived as limiting, both in terms of the potential of the materials (aesthetics and function) and their possible inhibition of the development of ideas. Perhaps getting a pile of felt in different colours and thicknesses does not trigger deep ideas. Here, redesign and material reuse may have an important role.

\section{An interdisciplinary approach}

When categorising the data, we tried to apply a perspective in which we focused on problem solving and knowledge of electronics and materials. Sorting the data was difficult, as they go crosswise, so the analysis is complex. They are obvious fusions of different but coherent elements. This also mirrors the complexity of the working process. Sennett (2008) describes the rhythm between problem solving and problem finding as an instant relation. This element can be found in the participants' working process. It is not a linear or fixed process with one single answer. One solution may open new ideas and combinations of skills and knowledge relying on both design elements and electronic knowledge. Etextiles are a complex, transverse and interdisciplinary field. Being able to teach about all these subjects can be challenging. This study is based on one workshop held at a single institute at the university. However, because of the interdisciplinary nature of the workshop, collaboration with other institutes at the university could have been fruitful. A similar workshop could be the starting point for an interdisciplinary project held at primary and secondary schools combining arts with STEM. Kafai et al. (2014) argue that e-textiles open the door for different traditional disciplines based on the co-presence of transparency, aesthetics and gender. When crossing disciplinary boundaries, students get the chance to develop an interdisciplinary knowledge bank. This approach, which involves transparency between disciplines, may open a broader idea phase, with an increased understanding of what can be created, and can lead to richness and diversity in the products developed.

E-textiles have the potential to strengthen creativity, enhance crafting skills and encourage discussions of design learning and sustainability in an educational context. Whether in makerspaces or schools, e-textiles can strengthen reflection on practice, as they enforce awareness about what is known and unknown and about what new skills are needed to solve an upcoming problem, thereby expanding the existing knowledge base. An e-textile project can be about renewing an old garment, adding new functions or repairing or designing something from scratch. This requires at least some basic skills not only in sewing and electronics but also in programming. Planning is key to avoiding short circuits and creating something that holds. Approaches concerning problem finding and problem solving are part of the process. A creative process usually requires sketching of the circuits and the design. This project can be time consuming, and one should be able to stay with the problem. To teach an e-textile project, one needs to have competence in a broad combination of disciplines and fields, which include programming and computational thinking, an emerging part of the school curricula. These changes in the curricula challenge the basic knowledge and skills typical for the Art and Crafts subject.

\section{REFLECTING ON THE PROJECT-MOVING FORWARD}

This study was conducted at the researcher's workplace. Alvesson (2003) has warned about blind spots when conducting such a study. In this case, this can involve taken-for-granted assumptions and biases concerning the teacher practice. It is our experience that these kinds of blind spots can grow over time within a specific institution. There may have been several blind spots that could have had an impact on the way the workshop was executed. During the workshop, it became clear that electronic circuits were something most of the participants did not have any experience with, or it was forgotten knowledge for others. On the one hand, the making of the bracelet was a simple way of gaining experience with and understanding electronic circuits. On the other hand, maybe it was not enough for all the participants. Perhaps more time spent learning basic electronics would be a methodical move. The assembly of all the components, especially the importance of the conductive sewing thread not touching other conductive threads and assembling conductive threads into different layers of textile, is something that could be quite complicated. This is something the teacher of the workshop assumed the participants 
understood, as they were experienced teachers in Art and Crafts. However, they may have never been concerned about avoiding threads to touch other threads, as this would not be an issue with regular sewing thread. These different matters concern the assumptions, biases and preconceptions of the teacher at the workshop, the main author. Further development of the workshop will involve striking a balance between the instruction part and the time given to the participants for creative explorative work.

The experiences drawn from the workshop may not only shed light on an established tradition of teaching but also guide the formal frames for continuing graduation courses. In hindsight, several ideas on how to further develop this type of workshop on e-textiles are emerging. This study relies on one specific workshop held at the university. The participants were trained teachers in Art and Crafts. The findings reveal a need for further research on this topic. E-textiles as a mash-up involving time, materials and issues on sustainability should be further explored. As the study is motivated by changes in the curricula for primary and secondary schools, it would be of interest if further studies were conducted in primary and secondary school projects, as well. One important question for further research is whether an interdisciplinary approach to learning in Art and Crafts, such as an e-textile project, may not only contribute to enhancing students' abilities for problem solving and creative thinking but also strengthen their awareness of issues concerning environmental impact and sustainability. These issues should also be followed up at the university level. Collaboration with other departments at the university, such as IT or electronics, can form the foundation for advanced interdisciplinary projects and design processes involving both students and teachers. However, this demands much more planning and facilitation compared with a one-day workshop. This also requires dedicated teachers and researchers working together, expanding discipline-based borders. Working together with colleagues in interdisciplinary projects can be a fruitful way to explore e-textiles in an educational context. 


\section{REFERENCES}

Alvesson, M. (2003). Methodology for close up studies-struggling with closeness and closure. Higher Education, 46(2), 1167-1193. https://link.springer.com/content/pdf/10.1023/A:1024716513774.pdf

Barefoot. (n.d.). Computational thinking concepts and approaches. Barefoot. http://barefootcas.org.uk/barefootprimary-computing-resources/concepts/computational-thinking

Berland, M. (2017). Making, tinkering, and computational literacy. In K. Peppler, E. R. Halverson, \& Y. B. Kafai, Makeology-Makers as learners 2 (pp. 196-205). Routledge.

Bocconi, S., Chioccariello, A., Dettori, G., Ferrari, A., \& Engelhardt, K. (2016). Developing computational thinking in compulsory education. Publications Office of the European Union. http://doi.org/10.2791/792158

Connor, A., Karmokar, S., \& Whittington, C. (2015). From STEM to STEAM: Strategies for enhancing engineering \& technology education. International Journal of Engineering Pedagogy, 5(2), 37-47. https://www.learntechlib.org/p/207460/

Dunin-Woyseth, H. (2008). More than a quarter of a century. The doctoral programme at Oslo School of Architecture and Design: Notes in the development of education since 1981. FormAkademisk Forskningstidsskrift for design og designdidaktikk, 1(1), 3-18. https://journals.hioa.no/index.php/formakademisk/article/view/117

Dunin-Woyseth, H., \& Michl, J. (2001). Towards a disciplinary identity of the making professions: An introduction. In H. Dunin-Woyseth \& J. Michl (Eds.), Towards a disciplinary identity of the making professions (pp. 120). Oslo School of Architecture.

Dunin-Woyseth, H., \& Nielsen, L. M. (2004). From Apprentice to Master: Some Notes on Educating Design Scholars and Developing Design Scholarship. In L. M. Nielsen (Ed.), DesignDialog - designforskning i et demokratisk perspektiv (pp. 15-25). Høgskolen i Oslo.

Fauske, L. B. (2013). Making scholarship: Describing the field of inquiry and the research approach. In J. B. Reitan, P. Lloyd, E. Bohemia, L. M. Nielsen, I. Digranes, \& E. Lutnæs (Eds.), Proceedings of the 2nd international conference for design education researchers, 14-17 May 2013, Oslo, Norway (pp. 508-517). ABMmedia AS.

Fauske, L. B. (2016). Reforhandling av kunnskapsgrunnlag. Forskning og fagutvikling med utspring i designdidaktikk [Renegotiation of the knowledge base. Research and field specific development in art and design education]. Techne Series - Research in Sloyd Education and Craft Science A, 23 (2), 50-68. https://journals.hioa.no/index.php/techneA/article/view/1560/1569

Holley, K. A. (2009). Special issue: Understanding interdisciplinary challenges and opportunities in higher education (ASHE Higher Education Report, v35, nr2). Hoboken. https://doi.org/10.1002/aehe.3502

Kafai, Y. B., Fields, D. A., \& Searle, K. A. (2014). Electronic textiles as disruptive designs: Supporting and challenging maker activities in school. Harvard Educational Review, 84(4), 532-556. https://doi.org/10.17763/haer.84.4.46m7372370214783

Klepp, I. G., \& Tobiasson, T. S. (2020). Lettkledd - velkledd med lite miljøbelastning [Well-dressed with little environmental impact]. Bokvennen Forlag.

Lutnæs, E. (2015). Imagining the unknown-Responsible creativity for a better tomorrow. FormAkademisk Forskningstidsskrift for design og designdidaktikk, 8(1), 1-15. https://doi.org/10.7577/formakademisk.1404

Lutnæs, E., \& Fallingen, N. (2017). Bærekraftig utvikling gjennom skapende praksis [Art and Craft education for sustainable development]. FormAkademisk - Forskningstidsskrift for design og designdidaktikk, 10(3), 119. https://doi.org/10.7577/formakademisk.1825

Ryle, G. (2000). The concept of mind. Penguin Books. 
Scardamalia, M., \& Bereiter, C. (2010). A brief history of knowledge building. Canadian Journal of Learning and Technology, 36(1), 1-16.

Sennett, R. (2008). The Craftsman. Yale University Press.

Schön, D. A. (1983). The reflective Practitioner. How professionals think in action. Basic Books.

Searle, K. A., Fields, D. A., \& Kafai, Y. B. (2016). Is sewing a "girl's sport"? Addressing gender issues in making with electronic textiles. In K. Peppler, E. R. Halverson, \& Y. B. Kafai (Eds.), Makeology-Makers as learners 2 (pp. 72-84). Routledge.

Udir. (2019). Algoritmisk tenkning [Computational thinking]. Utdanningsdirektoratet. https://www.udir.no/kvalitet-og-kompetanse/profesjonsfaglig-digital-kompetanse/algoritmisk-tenkning/

Udir. (2020a). Læreplan i kunst og håndverk (KHV01-02) [Art and Craft curriculum]. Utdanningsdirektoratet. https://www.udir.no/lk20/khv01-02

Udir. (2020b). Skaperglede, engasjement og utforskertrang [The joy of creating, engagement and the urge to explore]. Utdanningsdirektoratet. https://www.udir.no/lk20/overordnet-del/opplaringensverdigrunnlag/1.4-skaperglede-engasjement-og-utforskertrang/

Udir. (2020c). Bærekraftig utvikling [Sustainable development]. Utdanningsdirektoratet. https://www.udir.no/lk20/overordnet-del/prinsipper-for-laring-utvikling-og-danning/tverrfagligetemaer/2.5.3-barekraftig-utvikling/

Wing, J. M. (2017). Computational thinking's influence on research and education for all. Italian Journal of Educational Technology, 25(2), 7-14. https://doi.org/10.17471/2499-4324/922 